\title{
Enzyme blood profile in lactating cows of different bulls' genetic lines
}

\author{
V.I. Eremenko*, Yu.I. Gatilova, A.V. Blednova, S.Yu. Steblovskaya, and G.I. Shvets \\ Kursk State Agricultural Academy named after II Ivanov, K.Marksa st., 70 305021, Kursk, Russia
}

\begin{abstract}
Scientific and production experiments were carried out on lactating cows of the Simmental breed. 4 groups of cows derived from different lines of bulls Romulus, Redad, Huxle, and Honig were formed for the experiment. Each group contained 10 heads. The level of dairy productivity of experimental cows was the same and amounted to about 11 thousand $\mathrm{kg}$ of milk per lactation. The keeping conditions for the animals were the same. Feeding levels were consistent with their dairy productivity. Blood for the study was taken once a month prior to morning feeding. The following were determined in blood samples: total protein, alanine aminotransferase (ALT), aspartate aminotransferase (AAT), alkaline phosphatase (AP) and lactic dehydrogenase (LDH). During lactation, the highest level of total protein, the activity of ALT, AAT, AP, LDH was observed at the peak of lactation, followed by their decrease by the end of lactation regardless of cows' genetic affiliation. Relatively higher levels of total protein and ALT, AAT and LDH activity have been observed in lactating cows of the bull line Romulus relative to cows of the bull lines Redad, Huxle and Honig. There were no differences within the cows' genetic lines in the activity of alkaline phosphatase.
\end{abstract}

\section{Introduction}

Modern breeding is aimed at selecting animals by certain traits. In breeding terms, animals combining desirable traits are of special value [1]. However, the traditional selection system of genetically valuable animals often does not consider their interior biochemical features, which reflect the focus of metabolic processes occurring in the body. Since blood enzymes and related biochemical metabolic features are encoded in genes, it can be expected that the biochemical features of animals will be closely related to their economic traits and reflect their genetic potential $[2,3,4,5]$. One of these directions in biochemical genetics is the study of blood enzymes activity.

As it is known, the action of genes is carried out through enzyme systems, which affect the overall metabolism and thereby cause a certain level of productivity. The most accessible material for the interior indicators' assessment is blood; its research can be used to identify biochemical tests in breeding work with dairy cattle $[6,7,8,9]$. In this regard, key enzymes such as ALT, AAT, AP, and LDH are of greatest interest.

* Corresponding author: vic.eriomenko@yandex.ru 
ALT and AAT transaminases in the body catalyze reversible transamination reactions, which are a key link in protein metabolism. These enzymes are directly involved in the transfer of hydrogen and amino groups from amino acids to ketonic acids, and thereby participate in amino acid metabolism. The activity of alkaline phosphatase is associated with the regulation of cellular permeability - resorption of glucose and lipids in the small intestine occurs under its influence. The lactate dehydrogenase enzyme contains zinc in its composition. The main function of this enzyme is the catalysis of lactic acid oxidation to pyruvate [10]. There is a small number of works devoted to the study of genetic features of animals' interior [11, 12], but complex studies of blood enzymes in lactating cows of different genetic origin are absent. In this regard, this study is relevant.

Purpose. The aim of the study was to determine the dynamics of total protein in blood, the activity of alanine aminotransferase, aspartate aminotransferase, alkaline phosphatase and lactate dehydrogenase enzymes in lactating cows obtained from different bull lines.

\section{Research materials}

Scientific and production experiments were carried out on lactating cows of the Simmental breed. 4 groups of cows derived from different lines of bulls Romulus, Redad, Huxle, and Honig were formed for the experiment. Each group contained 10 heads. The level of dairy productivity of experimental cows was the same and amounted to about 10 thousand $\mathrm{kg}$ of milk per lactation. The keeping conditions for the animals were the same. Feeding levels were consistent with their dairy productivity. During lactation, blood for the study was taken once a month prior to morning feeding. Total protein was determined in blood samples on a refractometer. Alanine aminotransferase (ALT), aspartate aminotransferase (AAT), alkaline phosphatase (AP) and lactate dehydrogenase (LDH) enzymes were determined using reagents by "Bios systems". Research was conducted on the biochemical analyzer Sapphire 400. The obtained results of the study were subjected to biometric processing by the variational statistics method.

\section{Results of the study}

Total protein. The obtained study results of total protein in the blood of lactating cows obtained from different bull lines are shown in Figure 1.

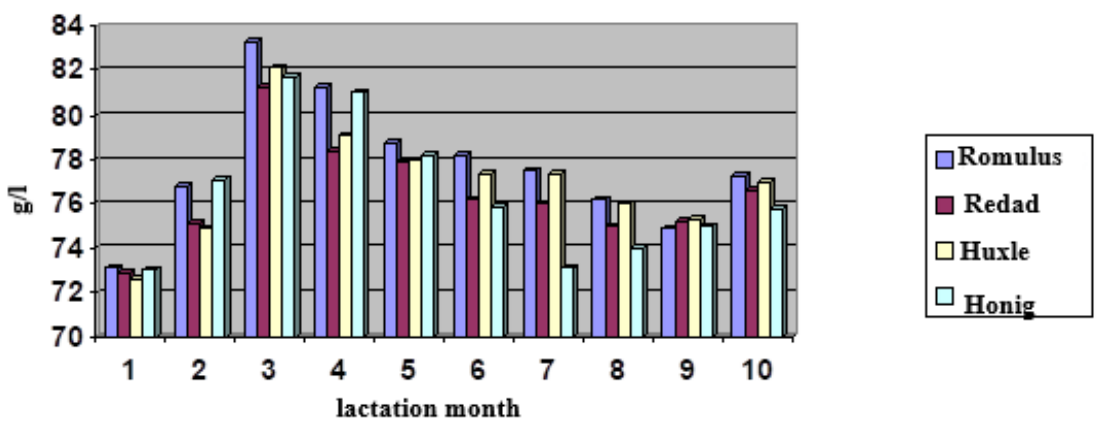

Fig. 1. Dynamics of total protein in the blood of lactating cows of different genetic bull lines.

As can be seen from the given data, the total protein level in the blood at the first month of lactation in experimental cows was approximately at the same level and was in the range 
from $72,6 \pm 2.4$ to $73.1 \pm 2.2 \mathrm{~g} / \mathrm{l}$. Further during lactation, the concentration of total protein in animals' blood in all experimental groups increased. So, in the second month of lactation this indicator in cows obtained from the bull lines Romulus, Redad, Huxle and Honig, the concentration of total protein amounted to $76.8 \pm 2.9 \mathrm{~g} / 1,75.1 \pm 2.7 \mathrm{~g} / 1,74.9 \pm 2.7 \mathrm{~g} / \mathrm{l}$ and $77.1 \pm 3.0 \mathrm{~g} \backslash 1$, respectively. The third month of lactation showed the highest level of total protein in the blood of lactating cows regardless of their genetic affiliation. During this lactation period, the concentration of total protein in the blood of cows belonging to the bull lines Romulus, Redad, Huxle and Honig was 83.3 $\pm 3.0 \mathrm{~g} / 1,81.2 \pm 2.8 \mathrm{~g} / 1,82.1 \pm 2.7 \mathrm{~g} / 1,81.7 \pm$ $3.1 \mathrm{~g} / \mathrm{l}$ respectively. Increases in total protein in cows of the bull lines Romulus, Redad, Huxle and Honig relative to the first month of lactation occurred by $13.95,11.3 \%, 13.0 \%$ and $11.9 \%$. From the fourth to ninth month of lactation, the level of total protein in the blood in all experimental cows gradually decreased. At the 9th month of lactation, its concentration in cows of the bull lines Romulus, Redad, Huxle and Honig amounted to $74.9 \pm 2.8 \mathrm{~g} / 1,75.2 \pm 3.0 \mathrm{~g} / 1,75.3 \pm 2.7 \mathrm{~g} / 1$ and $75.0 \pm 2.8 \mathrm{~g} / 1$, respectively. In relation to the maximum level of total protein that we observed at the peak of lactation, decreases by the 9th lactation month in cows of the bull lines Romulus, Redad, Huxle and Honig amounted to $11.2 \%, 7.9 \%, 9.0 \%$ and $8.9 \%$ respectively. At the end of lactation, at the 10 th month in relation to the 9th, there was an increase in total blood protein in all experimental animals. Apparently, this increase is associated with an increase in the pregnancy period and the growth of the fetus in experimental cows. The level of total protein at the 10th month of lactation in cows of the bull lines Romulus, Redad, Huxle and Honig was $77.3 \pm 3.0 \mathrm{~g} / \mathrm{l}$, $76.6 \pm 2.9 \mathrm{~g} / 1,77.0 \pm 2.5 \mathrm{~g} / 1$ and $75.8 \pm 2.7 \mathrm{~g} / \mathrm{l}$. In the comparative aspect of experimental animals, it is evident that significant differences in the level of total protein in the blood in cows of different bull lines have not been established. However, it should be noted that marginally higher rates of total blood protein were noted in cows of the bull line Romulus relative to the compared cow groups.

Alanine aminotransferase (ALT). From the data shown in Figure 2, it is clear that at the beginning of lactation the activity of ALT in experimental cows was at the level from $227.0 \pm 5.4$ nkat/l to $232,5 \pm$ nkat/l.

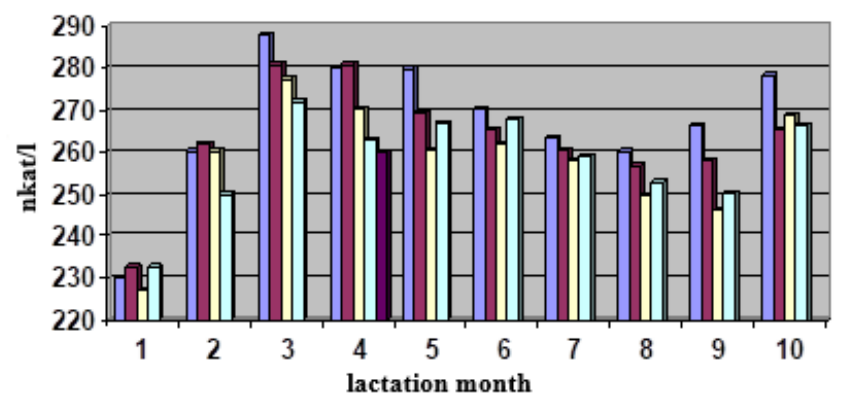

\begin{tabular}{|l|}
\hline$\square$ Romulus \\
$\square$ Redad \\
$\square$ Huxle \\
$\square$ Honig \\
\hline
\end{tabular}

Fig. 2. Dynamics of alanine aminotransferase in the blood of lactating cows of different genetic bull lines.

In the third month of lactation, during the period of maximum milk yield, the ALT activity in all experimental groups of lactating cows was at the highest level and in the cows of the bull lines Romulus, Redad, Huxle and Honig amounted to $287.8 \pm 4.9$ nkat/l, $280.8 \pm 5.1 \mathrm{nkat} / \mathrm{l}, 277.4 \pm 5.2 \mathrm{nkat} / \mathrm{l}$ and 272.1 $\pm 5.0 \mathrm{nkat} / \mathrm{l}$, respectively. After the third month, there was a gradual decline in ALT activity. This decrease occurred until the 9 th month of lactation. At the 9th month of lactation, ALT activity was in the cows of the bull lines Romulus, Redad and Honig was at 266.4 $\pm 4.7 \mathrm{nkat} / 1,258.3 \pm 5.0 \mathrm{nkat} / 1,246.1 \pm 5.0 \mathrm{nkat} / \mathrm{l}$ and 
$250.3 \pm 5.2$ nkat/1, respectively. In relation to the 9th month, on the 10th lactation month there was an increase in ALT activity in cows of the bull lines Romulus, Redad, Huxle and Honig to $278.4 \pm 5.1$ nkat/l, 265.6 \pm 4.4 nkat/l, 268.8 \pm 4.6 nkat/l, 266.4 \pm 4.8 nkat/l, respectively. Apparently, this phenomenon is also associated with the development and growth of the fetus and increased protein metabolism in the synthesis of which ALT is involved. Analyzing data between experimental cow groups, it should be noted that the activity of ALT in lactating cows of different bull's genetic origin is not the same. Relatively higher activity rates of this enzyme were observed in cows of the Romulus bull line. There were statistically reliable differences at 3,4,9 and 10 months of lactation in cows of the Romulus bull line with respect to the cows of the Honig bull line $(\mathrm{P}<0.05)$. At 4.5 and 9 months of lactation, statistically significant differences were established between the cows of the bull lines Romulus and Huxle $(\mathrm{P}<0.05)$. Similar changes were also observed in the activity of aspartate aminotransferase (AAT) figure 3.

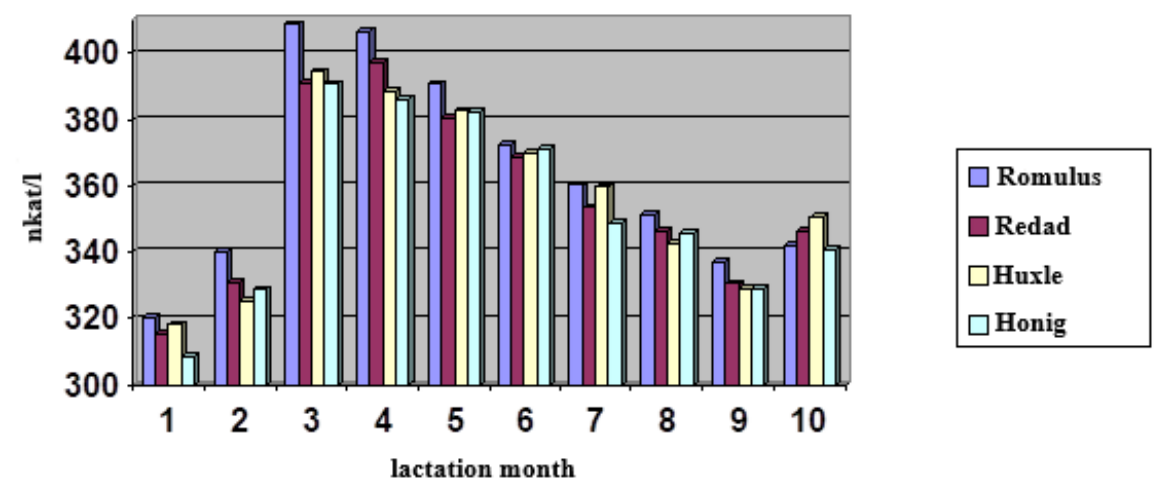

Fig. 3. Dynamics of aspartate aminotransferase in the blood of lactating cows of different genetic bull lines.

So, in the first month of lactation, AAT activity in cows of the bull lines Romulus, Redad, Huxle and Honig was 320.3 \pm 5.0 nkat/1, 325.4 $\pm 5.6 \mathrm{nkat} / 1,318,2 \pm 5.3 \mathrm{nkat} / \mathrm{l}$. As with previous indicators, AAT activity was also the highest at peak lactation. So, in cows of the bull line Romulus, the enzyme activity was $408.6 \pm 6.0 \mathrm{nkat} / \mathrm{l}$, in cows of the bull line Redad - 390,9 $\pm 6.2 \mathrm{nkat} / 1$, in cows of the bull line Huxle - 394,4 $\pm 6.8 \mathrm{nkat} / 1$, and the cows of the bull line Honig $-390.7 \pm 5.7$ nkat/l. Further during lactation up to the 9 th month there was a decrease in AAT activity in all experimental cows. At the 9th month of lactation, this indicator in cows of the bull line Romulus was $337.0 \pm 5.8 \mathrm{nkat} / 1$, in cows of the bull line Redad - 330.5 $\pm 5.7 \mathrm{nkat} / \mathrm{l}$, in cows of the bull line Huxle $-328.8 \pm 5.8 \mathrm{nkat} / \mathrm{l}$, in cows of the Honig bull line $-329.0 \pm 5.6 \mathrm{nkat} / \mathrm{l}$. At the 10th month of lactation, there was an increase in AAT activity in cows of the bull line Romulus to $342.1 \pm 4.8 \mathrm{nkat} / 1$, in cows of the bull line Redad - to the level of $346.3 \pm 4.9 \mathrm{nkat} / \mathrm{l}$, in cows of the bull line Huxle - to the level of $350.7 \pm 6.0 \mathrm{nkat} / \mathrm{l}$, in cows of the bull line Honig - to the level of $340.8 \pm 5.7 \mathrm{nkat} / \mathrm{l}$. Considering the obtained data in a comparative aspect between experimental groups, it should be noted that relatively higher AAT activity during all lactation periods was noted in cows of the bull line Romulus. Statistically reliable differences on the 3rd month of lactation were established between the cows of the bull lines $\operatorname{Romulus}$ and $\operatorname{Redad}(\mathrm{P}<0.05)$, as well as between the cows of the bull lines Romulus and Honig $(\mathrm{P}<0.05)$. There were also statistically significant differences between the cows of the bull lines Romulus and Huxle $(\mathrm{P}<0.05)$, as well as between the cows of the bull lines Romulus and Honig $(\mathrm{P}<0.05)$ at the 
4th month of lactation. During other lactation periods, the differences between experimental groups of cows were not statistically reliable $(\mathrm{P}>0.05)$.

Dynamics of alkaline phosphatase activity in the blood of lactating cows belonging to different bull lines is shown in Figure 4.

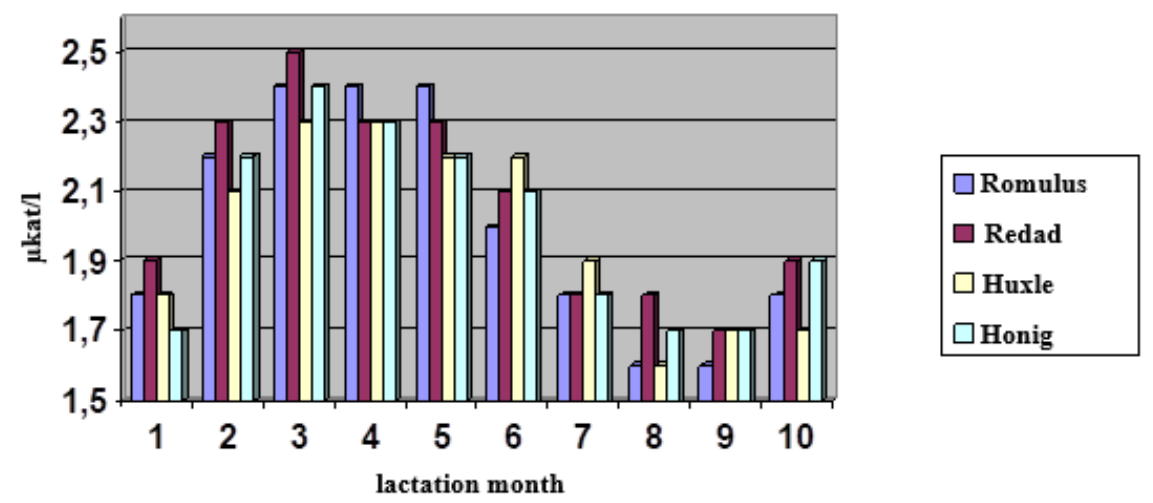

Fig. 4. Dynamics of alkaline phosphatase in lactating cows of different genetic bull lines.

In the first month of lactation, the activity of alkaline phosphatase in experimental cows was at the level from $1.7 \pm 0.2 \mu \mathrm{kat} / 1$ to $1.9 \pm 0.2 \mu \mathrm{kat} / 1$. By the second month of lactation, the activity of this enzyme increased in all groups of lactating cows and was at a level from $2.1 \pm 0.2 \mu \mathrm{kat} / 1$ to $2.3 \pm 0.3 \mu \mathrm{kat} / \mathrm{l}$. The enzyme's highest activity was observed at peak lactation, which corresponded to the third month of lactation. So, in cows of the bull line Romulus, the AP activity during this period was $2,4 \pm 0.2 \mu \mathrm{kat} / \mathrm{l}$, in cows of the bull line Huxle - 2,3 $\pm 0.2 \mu \mathrm{kat} / 1$ and in cows of the bull line Honig - 2,4 $\pm 0.2 \mu \mathrm{kat} / 1$. Relatively high enzyme activity in lactating cows was preserved at 4 and 5 months of lactation. So, on the fourth month of lactation, the activity of AP in cows of the bull lines Redad, Huxle and Honig was the same and amounted to $2,3 \pm 0.2 \mu \mathrm{kat} / 1$, and in cows of the bull line Romulus $2,4 \pm 0.3 \mu \mathrm{kat} / 1$. At the 5 th month of lactation, the AP activity did not change significantly and was at the level from 2.2 to $2.4 \mu \mathrm{kat} / \mathrm{l}$. By the 7 th month of lactation, the value of the AP activity changed towards decrease. So, in the cows of the bull lines Romulus, Redad and Honig, the level of enzyme activity was the same and amounted to $1,8 \pm 0.2 \mu \mathrm{kat} / 1$, and the cows of the bull line Huxle - 1,9 $\pm 0.3 \mu \mathrm{kat} / \mathrm{l}$. By the 8th and 9th month of lactation, the indicators of the AP activity continued to change. So, on the 8th and 9th months of lactation, the activity of the enzyme was at the level of 1.6-1.8 $\mu \mathrm{kat} / 1$. By the 10 th month of lactation, there was an increase in the AP activity. In the cows of the bull lines Redad and Honig, the enzyme activity was the same and amounted to $1.9 \pm 0.3 \mu \mathrm{kat} / \mathrm{l}$, and the cows of the bull line Romulus and Huxle - 1.8 $\pm 0.2 \mu \mathrm{kat} / 1,1.7 \pm 0.2 \mu \mathrm{kat} / 1$ and $1.7 \pm 0.2 \mu \mathrm{kat} / \mathrm{l}$, respectively.

Studies of lactate dehydrogenase activity in the blood of lactating cows obtained from different bull lines are shown in Figure 5 . 


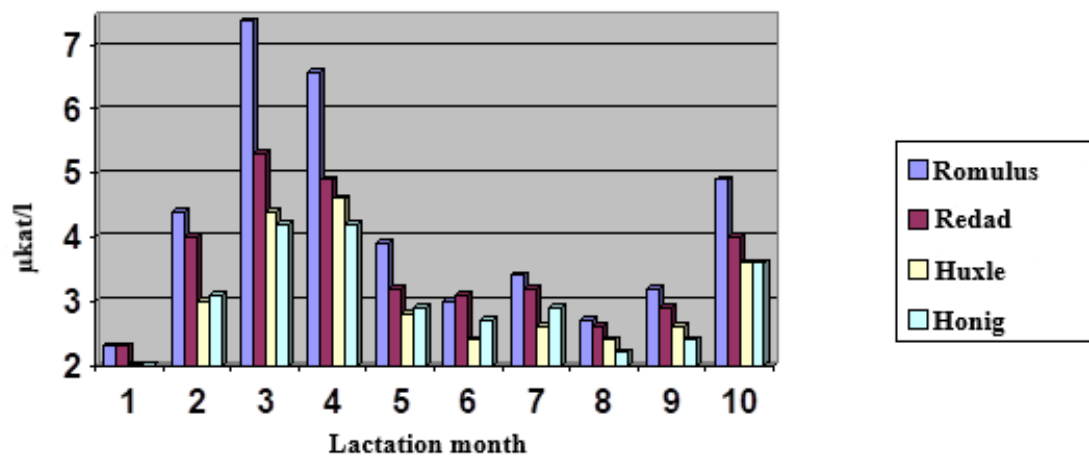

Fig. 5. Dynamics of lactate dehydrogenase activity in the blood of lactating cows of different genetic bull lines.

As evidenced by the given data, at the first month of lactation the LDH activity was at the level from $1.8 \pm 0.4 \mu \mathrm{kat} / 1$ to $2.3 \pm 0.5 \mu \mathrm{kat} / \mathrm{l}$. With further increase in milk productivity until the third month of lactation, the activity of the enzyme increased. At the peak of lactation, which corresponded to the third month, the LDH activity was the highest thorugh the entire observation period and was at the level from $4.2 \pm 0.8 \mu \mathrm{kat} / 1$ to $7.4 \pm 1,1 \mu \mathrm{kat} / 1$. In cows of the bull line Romulus, the LDH activity during this period amounted to $7.4 \pm 1.1$ $\mu \mathrm{kat} / \mathrm{l}$. In cows of the bull line Redad - 5,3 $\pm 0.9 \mu \mathrm{kat} / 1$, cows of the bull line Huxle $-4,4 \pm 0.8$ $\mu \mathrm{kat} / 1$, the cows of the Honig bull line $-4,2 \pm 0.8 \mu \mathrm{kat} / \mathrm{l}$. During further lactation until the 9 th month inclusively, there was a decrease in the activity of the enzyme. So, on the 8th month, LDH activity in the blood of cows of the bull line Romulus was $2.7 \pm 0.6 \mu \mathrm{kat} / \mathrm{l}$, in cows of the bull line Redad $-2,6 \pm 0.5 \mu \mathrm{kat} / 1$, in cows of the Honig bull line $-2,2 \pm 0.5 \mu \mathrm{kat} / 1$. Further to the end of lactation, there was an increase in LDH activity observed. At the 10th month, the level of enzyme activity in cows of the bull line Romulus and Redad was $4.9 \pm 0.8 \mu \mathrm{kat} / \mathrm{l}$ and $4.0 \pm 0.7 \mu \mathrm{kat} / \mathrm{l}$, respectively. In the cows of the bull lines Huxle and Honig, LDH activity was the same and amounted to $3.6 \mu \mathrm{kat} / \mathrm{l}$. When comparing LDH activity rates between experimental cow groups, it should be noted that higher LDH activity values were in cows of the bull line Romulus at the $3 \mathrm{rd}$ and 4 th months of lactation relative to the data of Huxle and Honig bull line cows. The differences were statistically reliable $(\mathrm{P}<0.05)$.

\section{Conclusions}

1. During lactation, the highest level of total protein, activity of alanine aminotransferase, aspartate aminotransferase, alkaline phosphatase, lactate dehydrogenase were observed at the peak of lactation followed by their decrease by the end of lactation regardless of the genetic affiliation of cows.

2. Relatively higher levels of total protein and activity of alanine aminotransferase, aspartate aminotransferase and lactate dehydrogenase were noted in lactating cows of the Romulus bull line relative to cows of bull lines Redad, Huxle and Honig. There were no differences within the genetic lines of cows in the activity of alkaline phosphatase.

\section{References}

1. A.A. Torekhanov, Papers of RAAS, 3, 63-65 (1993) 
2. A.G. Kudrin, Agricultural Biology, 4, 45-49 (2001)

3. A.G. Kudrin, Dairy and Meat Cattle, 4, 24-25 (2001)

4. E.K. Merkuryeva, V.I. Volgin, L.R. Trifonova, Proceedings of VASKhNIL, 10, 26-28 (1972)

5. A.G. Kudrin, Blood enzymes and forecasting of livestock milk productivity, 142 (2006)

6. E.V. Eidrigevich, V.V. Raevskaya, Interior of farm animals, 254 (1978)

7. G.F. Yashchenko, Enzymes in medicine, food industry and agriculture, 240-247 (1968)

8. V.I. Eremenko, E.G. Rotmistrovskaya, EurAsian Journal of BioSciences, 13(1), 523527 (2019)

9. V.I. Eremenko, G.A. Gorozhankina, Yu.I. Gatilova, Bulletin of the Kursk State Agricultural Academy, 1, 79-82 (2021)

10. V.V. Yurkevich, Biological Sciences, 9 (81), 115 - 126 (1970)

11. V.I. Eremenko, Yu.V. Stasenkova, Bulletin of the Kursk State Agricultural Academy, 8, 187-188 (2015)

12. V.I. Eremenko, Yu.V. Stasenkova, Bulletin of the Orenburg State University, 11 (211) 31, 88-92 (2017) 